\title{
5-Azacytidine regulates matrix metalloproteinase-9 expression, and the migration and invasion of human fibrosarcoma HT1080 cells via PI3-kinase and ERK1/2 pathways
}

\author{
SEON-MI YU and SONG JA KIM \\ Department of Biological Sciences, College of Natural Sciences, \\ Kongju National University, Gongju 32588, Republic of Korea
}

Received April 29, 2016; Accepted June 21, 2016

DOI: $10.3892 /$ ijo.2016.3612

\begin{abstract}
Abnormal methylation of promoter $\mathrm{CpG}$ islands is one of the hallmarks of cancer cells, and is catalyzed by DNA methyltransferases. 5-azacytidine (5-aza C), a methyltransferase inhibitor, can cause demethylation of promoter regions of diverse genes. Epigenetic processes contribute to the regulation of matrix metalloproteinase (MMP) expression. However, little is known about the mechanisms and effects of 5-aza $\mathrm{C}$ on the invasive and migratory capacities of human fibrosarcoma HT1080 cells. In the present study, we found that 5-aza C induces MMP-9 activity, as determined by zymography. HT1080 cell proliferation was determined following 5-aza $\mathrm{C}$ administration by 3-(4,5-dimethylthiazol2-yl)-2,5-diphenyltetrazolium bromide assay. Cell cycle was examined by flow cytometry. 5-aza $\mathrm{C}$ treatment inhibited cell proliferation without affecting cell viability. Furthermore, 5-aza $\mathrm{C}$ significantly promoted migration and invasion of HT1080 cells. 5-aza C treatment enhanced phosphorylation of extracellular signal-regulated kinase (ERK) and phosphoinositide (PI)3-kinase/Akt, and their inhibitors blocked MMP-9 activity induction, and cellular invasion and migration. Together, these findings suggest that promoter methylation may be one of the mechanisms modulating MMP-9 levels in HT1080 cells, and that 5-aza C-induced MMP-9 production is associated with the activation of ERK and PI3-kinase/Akt signaling pathways.
\end{abstract}

Correspondence to: Professor Song Ja Kim, Department of Biological Sciences, Kongju National University, Daehakro 56, Gongju 32588, Republic of Korea

E-mail: ksj85@kongju.ac.kr

Abbreviations: MMPs, matrix metalloproteinases; 5-aza C, 5-azacytidine; ERK, extracellular signal-regulated kinase; PI3kinase, phosphoinositide 3-kinase; ECM, extracellular matrix; DNMTs, DNA methyltransferases; PD, PD 98059; LY, LY 294002

Key words: 5-azacytidine, matrix metalloproteinase-9, migration, invasion, HT1080 human fibrosarcoma cells

\section{Introduction}

Although biochemical and clinical studies have resulted in significant advance of our knowledge of cancer, we have not been able to find a cure for the disease. High invasive and metastatic capacities are critical characteristics of fibrosarcoma, a malignant mesenchymal tumor, that partially account for rapid disease progression and poor prognosis. However, the molecular mechanisms leading to the invasion and metastasis of fibrosarcoma are still poorly understood.

Recently, the crucial role of DNA methylation alterations in human carcinogenesis was emphasized (1). The development and progression of cancer is caused by both, genetic mutations and epigenetic changes, including DNA methylation and histone modifications (2). In mammals, DNA methylation primarily involves a covalent modification of cytosine residues of $\mathrm{CpG}$ dinucleotides (3). DNA methylation changes include locus-targeted hypermethylation and global hypomethylation (4). Covalent methylation of DNA CpG islands is catalyzed by methyltransferases that methylate C-5 of cytosine nucleotides. Global cytosine methylation patterns in the mammalian genome appear to be established by a complex interplay of at least three independently encoded DNA methyltransferases (DNMTs): DNMT1, DNMT3A and DNMT3B.

5-aza $\mathrm{C}$ is a methyltransferase inhibitor. It is incorporated into the DNA of rapidly growing tumor cells during replication and blocks DNA methylation by trapping DNA methyltransferases on DNA, leading to their intracellular depletion (5). 5-Aza C exerts diverse effects on gene expression (6) and cellular survival (7).

Matrix metalloproteinases (MMPs) are a class of proteolytic enzymes that degrade all extracellular matrix (ECM) components (8). These enzymes regulate the migration of various cancer cells across the ECM, cell growth, angiogenesis and apoptosis. All these processes are essential for the dissemination of neoplastic cells. The MMP family member MMP-9, can degrade collagen, the main component of vascular basement membrane (9). MMP-9 activity is modulated on several levels, including gene transcription (10), mRNA stability (11), secretion (12) and enzymatic activity. MMP-9 gene expression can be regulated by a variety of stimuli, such as interleukin (IL)-1 $\beta$, tumor necrosis factor $\alpha$, epidermal growth factor 
and phorbol esters $(13,14)$. However, the effects of 5-aza $\mathrm{C}$ on MMP-9 expression and activity in HT1080 cells have not been completely elucidated.

Therefore, we have studied the effects of 5-aza $\mathrm{C}$ on MMP-9 activity, migration and invasion. We demonstrated that 5-aza C enhances migration and invasion of HT1080 cells by activating MMP-9 via phosphoinositide (PI)3-kinase/Akt and extracellular signal-regulated kinase (ERK)1/2 signaling pathways.

\section{Materials and methods}

Reagents. 5-aza C was purchased from Sigma-Aldrich (St. Louis, MO, USA). PD 98059 (PD) was purchased from Calbiochem (San Diego, CA, USA) and LY 294002 (LY) was purchased from Tocris Bioscience (Bristol, UK).

Cell culture. Human fibrosarcoma HT1080 cells (KCLB no. 10121; Korean Cell Line Bank, Seoul, Korea) were grown in RPMI-1640 medium (Gibco/Invitrogen, Carlsbad, CA, USA) supplemented with $10 \%$ fetal bovine serum (FBS; Gibco-Invitrogen), penicillin (50 U/ml; Sigma-Aldrich) and streptomycin $(50 \mu \mathrm{g} / \mathrm{ml}$; Sigma-Aldrich), in a humid atmosphere, $5 \% \mathrm{CO}_{2}$ and $95 \%$ air at $37^{\circ} \mathrm{C}$.

MTT assay. Proliferation of HT1080 cells was determined using colorimetric 3-(4,5-dimethylthiazol-2-yl)-2,5-diphenyltetrazolium bromide (MTT) assay. Cells were seeded into 96-well plates $\left(0.5 \times 10^{5}\right.$ cells/well in $100 \mu \mathrm{l}$ medium $)$ and cultured for $24 \mathrm{~h}$. After an overnight incubation, the cells were treated with 5 -aza $\mathrm{C}$ concentration gradient $(0,5,10$, or $20 \mu \mathrm{M}$ ) for $24 \mathrm{~h}$, or with $10 \mu \mathrm{M} 5$-aza $\mathrm{C}$ for the indicated time periods, and then washed with phosphate-buffered saline (PBS). Thereafter, the medium was replaced by fresh medium (200 $\mu \mathrm{l}$ ) containing $0.5 \mathrm{mg} / \mathrm{ml} \mathrm{MTT}$, and the mixture was incubated for $4 \mathrm{~h}$ at $37^{\circ} \mathrm{C}$. Following the incubation, $100 \mu \mathrm{l}$ solubilization buffer $(10 \%$ SDS, $0.01 \mathrm{~N} \mathrm{HCl})$ was added to each well to terminate the MTT reaction and dissolve formazan crystals. After agitation for $1 \mathrm{~h}$ at room temperature, optical density of the solution in each well was measured at $595 \mathrm{~nm}$ using a microplate reader (Molecular Devices, Sunnyvale, CA, USA). Proliferation inhibition rate was calculated as: [1-A 595 (experimental well)/ $\mathrm{A}_{595}$ (control well)] x $100 \%$.

Wound-healing assay. HT1080 cell migration was determined by wound-healing assay (15). Briefly, HT1080 cells (5x10 $/$ well) were seeded into $35-\mathrm{mm}$ culture dish and after reaching $\sim 90 \%$ confluence, a scratch was made in the cells with a $10-\mu 1$ pipette tip. The remaining cells were washed with medium and incubated with 5 -aza $\mathrm{C}$ in the absence or presence of inhibitors for $24 \mathrm{~h}$. The migration distance of cells was then captured and the images were quantitatively analyzed using ImageJ software (National Institutes of Health, Bethesda, MD, USA). Distances between scratch edges were measured and statistically analyzed (see below).

Invasion assay. HT1080 invasion was determined with Transwell Matrigel system (16). Cells ( $1 \times 10^{5}$ cells/well) were cultured in the top chambers of 24-well Transwell plates (8.0 mm-pore; Corning Costar, Corning, NY, USA) and complete RPMI-1640 medium was added to the bottom chambers. After $24 \mathrm{~h}$, the cells on the surface of the top chamber membrane were removed with a cotton swab. Cells that had migrated to the bottom surface of the top chamber membranes were fixed with $95 \%$ methanol, stained with $1 \mathrm{mg} / \mathrm{ml}$ crystal violet and hematoxylin solution, and counted (20 random fields) under a microscope (magnification, x200). Each experiment was performed in triplicate and repeated at least twice.

Flow cytometry. Cells $\left(5 \times 10^{5}\right.$ cells $)$ were grown in $35-\mathrm{mm}$ culture dish to $\sim 80 \%$ confluence and starved in serum-free medium at $37^{\circ} \mathrm{C}$ for $12 \mathrm{~h}$. The cells were then treated with 5 -aza $\mathrm{C}$ for $24 \mathrm{~h}$ and harvested in trypsin-EDTA $(0.25 \%$, $\mathrm{pH}$ 7.2) buffer. Cells were washed with PBS prior to suspension in cold propidium iodide (PI) solution $(50 \mu \mathrm{g} / \mathrm{ml})$ in PBS (pH 7.4) containing RNase A $(0.1 \mathrm{mg} / \mathrm{ml})$ for $30 \mathrm{~min}$ in the dark. After incubation, cell apoptosis and cell cycle distribution were analyzed with a flow cytometer (Partec $\mathrm{GmbH}$, Munster, Germany).

Western blot analysis. Preparation of cell lysates and western blot analyses were performed as previously described (17). Briefly, equal amounts of proteins from whole cell lysates (20-30 $\mu \mathrm{g}$ ) were resolved by $8-12 \%$ SDS-polyacrylamide gel electrophoresis and transferred to a nitrocellulose membrane. The membrane was then incubated in blocking buffer comprising 5\% skimmed milk in Tris-buffered saline with Tween-20 (TBST), at room temperature for $1 \mathrm{~h}$. The blocked membrane was next incubated with primary antibodies, at $4^{\circ} \mathrm{C}$, overnight. The following primary antibodies were used: rabbit anti-DNMT-1 polyclonal antibody (1:1,000 dilution; Santa Cruz Biotechnology Inc., Santa Cruz, CA, USA; sc-20701); mouse anti-phospho-Akt polyclonal antibody (1:1,000 dilution; Cell Signaling Technology Inc., Danvers, MA, USA; \#9271); rabbit anti-Akt polyclonal antibody (1:1,000 dilution; Santa Cruz Biotechnology; \#9272); rabbit anti-phospho-p44/42 MAP kinase (pERK1/2) polyclonal antibody (1:1,000 dilution; Cell Signaling Technology; \#9101); rabbit anti-ERK-2 polyclonal antibody (1:1,000 dilution; Santa Cruz Biotechnology; sc-154). The membrane was washed three times (10 min each) with TBST, and then incubated with secondary antibodies, at room temperature, for $2 \mathrm{~h}$. The following secondary antibodies were used: anti-rabbit IgG antibody (1:3,000 dilution; SigmaAldrich; A0545); anti-mouse IgG antibody (1:3,000 dilution Enzo Life Sciences, Inc., Farmingdale, NY, USA; ADI-SAB100). The antigen-antibody complex was detected with an enhanced chemiluminescence detection kit (Dogen, Seoul, Korea). Protein band intensities were quantified by the ImageJ and normalized to internal $\beta$-actin control. Normalized values were plotted and are presented.

Zymographic assay of MMP-9 gelatinase activity. MMP-9 gelatinase activity in conditioned media was performed using SDS-PAGE zymography, as previously described (18). Briefly, HT1080 cells were split into 35-mm culture dish. After $24 \mathrm{~h}$, cells were serum-starved in RPMI-1640 medium (Gibco/Invitrogen) for additional $20 \mathrm{~h}$, and then treated with increasing concentrations of 5-aza $\mathrm{C}(0,5,10$ and $20 \mu \mathrm{M})$ for $24 \mathrm{~h}$. Subsequently, $30 \mu \mathrm{l}$ conditioned medium was mixed with reducing agent-devoid of $4 \mathrm{X}$ SDS sample buffer $(62.5 \mathrm{mM}$ 

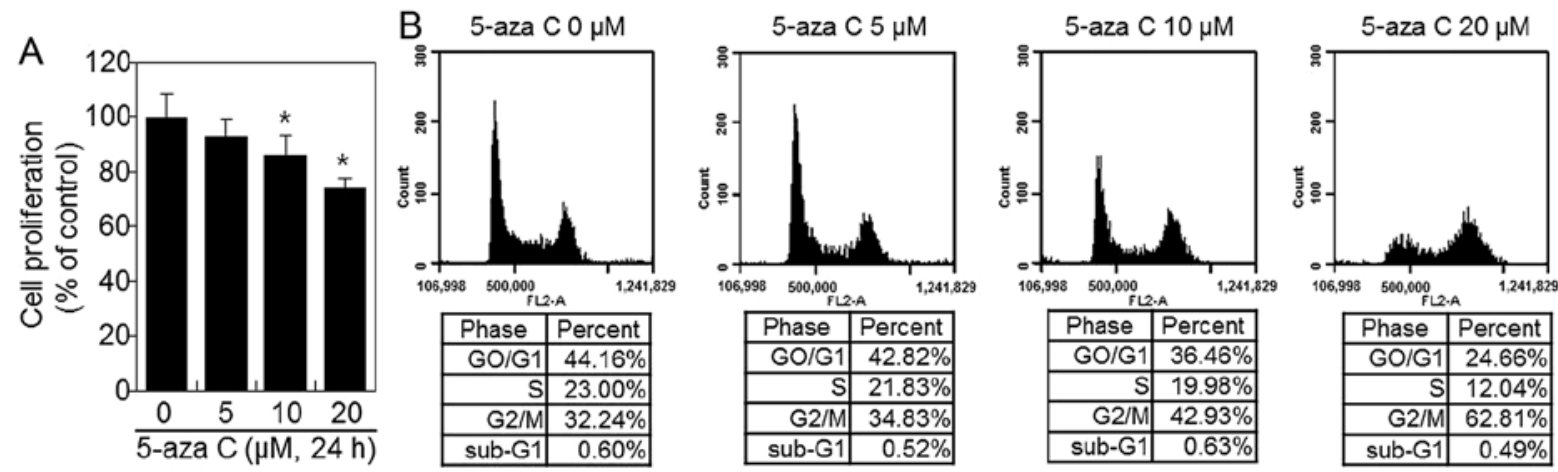

Figure 1. 5-Aza C inhibits proliferation of human fibrosarcoma HT1080 cells. HT1080 cells were treated for $24 \mathrm{~h}$ with the indicated concentrations $(5,10$ and $20 \mu \mathrm{M}$ ) of 5-aza C. (A) Cell proliferation, as determined by MTT assay. The data are from three independent experiments and are given as means \pm SEM. ${ }^{*} \mathrm{P}<0.05$ compared with control. (B) Cell cycle DNA distribution, as examined by FACS analysis. The data are representative of three similar experiments. Please see Materials and methods for details.
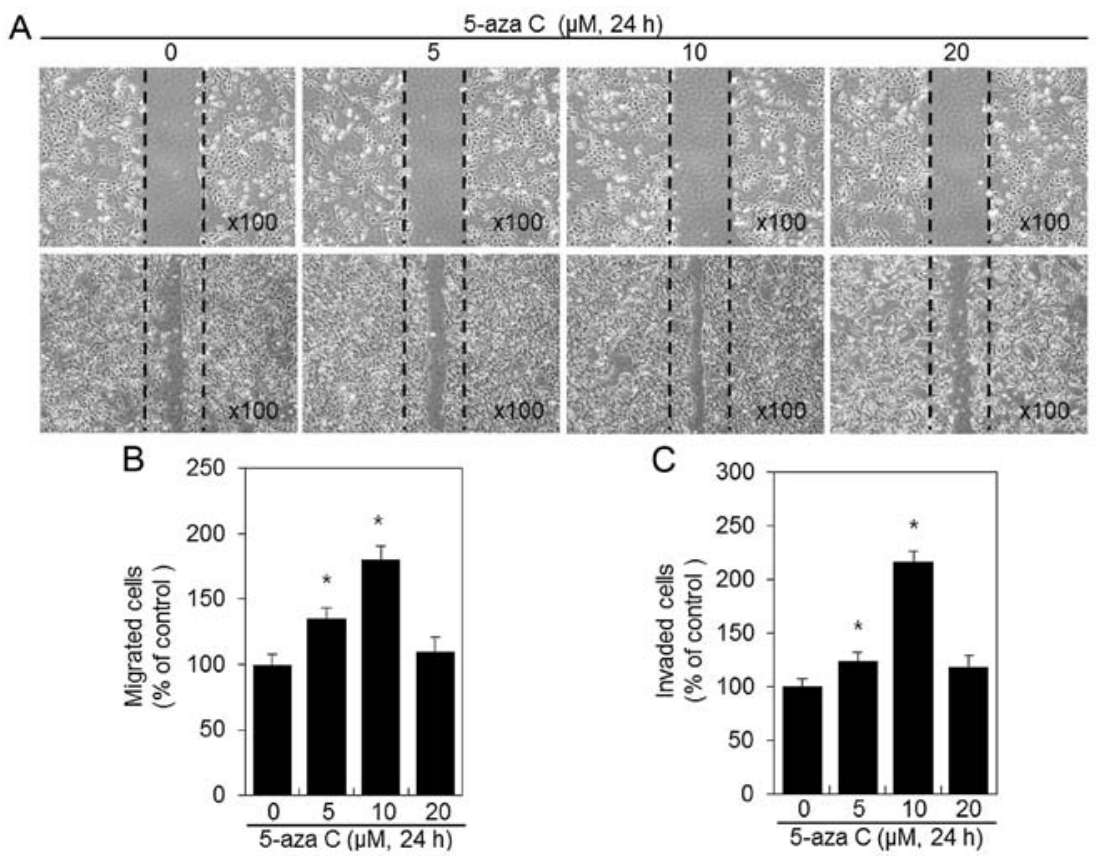

Figure 2. 5-Aza C treatment increases migration and invasion of HT1080 cells. (A-C) Confluent cell monolayers were scraped and then treated with the indicated concentrations of 5-aza C $(5,10$ and $20 \mu \mathrm{M})$ for $24 \mathrm{~h}$. (A) Cell migratory ability, as determined by wound-healing assay. The images are representative of three similar experiments. (B) Migrated cell numbers, determined by densitometric measurements with ImageJ. (C) HT1080 invasion ability, as determined by invasion assay. (B and C) The data are from three independent experiments and are given as means \pm SEM. "P<0.05 compared with control.

Tris, $4 \%$ SDS, $25 \%$ glycerol, $0.01 \%$ bromophenol blue, $\mathrm{pH}$ 6.8) and subjected to electrophoresis in 7.5\% SDS-PAGE gels containing $1 \mathrm{mg} / \mathrm{ml}$ gelatin (Sigma-Aldrich). After electrophoresis, gels were washed twice with $2.5 \%$ (v/v) Triton X-100 for $60 \mathrm{~min}$ at room temperature to remove SDS and subsequently incubated overnight at $37^{\circ} \mathrm{C}$ in a developing buffer containing $10 \mathrm{mM} \mathrm{CaCl}_{2}, 150 \mathrm{mM} \mathrm{NaCl}$, and $50 \mathrm{mM}$ Tris- $\mathrm{HCl}, \mathrm{pH} \mathrm{8.0,}$ for $24 \mathrm{~h}$. The gels were stained with $0.5 \%$ Coomassie brilliant blue R-250 in 10\% acetic acid (v/v) and 50\% methanol, for $\sim 1 \mathrm{~h}$, and then destained in 50\% methanol and 10\% acetic acid solution at room temperature to clearly visualize the digested bands. MMP-9 proteolytic activities were visualized as clear bands against blue background of stained gelatin.

Statistical analysis. Data are presented as means \pm SEM from three independent experiments and compared using one-way
ANOVA. For $\mathrm{P}<0.05$, differences were considered statistically significant and are indicated by an asterisk in the figures.

\section{Results}

5-Aza C inhibits the proliferation of HT1080 cells. To evaluate the effect of 5 -aza $\mathrm{C}$ on cellular proliferation, cells were cultured with increasing 5 -aza $\mathrm{C}$ concentrations $(5,10$ and $20 \mu \mathrm{M}$ ), as described in Materials and methods, and their viability was assessed by MTT assay. 5-Aza C inhibited proliferation of cells in a dose-dependent manner (Fig. 1A). We next performed FACS analysis to investigate the effect of 5-aza C on the cell cycle (Fig. 1B). FACS analysis revealed that 5-aza C induced $\mathrm{G}_{2} / \mathrm{M}$ phase arrest (Fig. 1B). Only $32.2 \%$ untreated control HT1080 cells were in $\mathrm{G}_{2} / \mathrm{M}$ phase. However, $24 \mathrm{~h}$ of treatment with 5, 10 and $20 \mu \mathrm{M} \mathrm{5}$-aza $\mathrm{C}$, the proportion of 
A

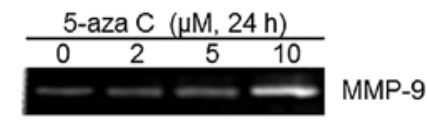

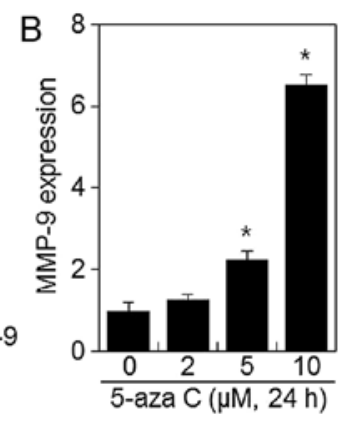

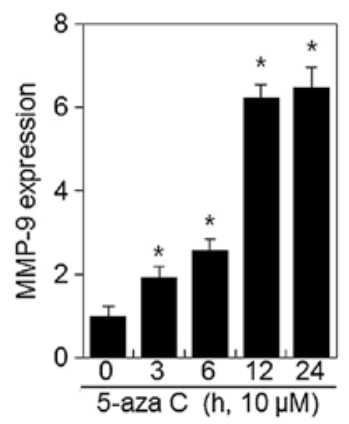

Figure 3. 5-Aza C treatment induces MMP-9 expression. HT1080 cells were treated for $24 \mathrm{~h}$ with the indicated 5-aza C concentrations (A, upper image; B, left), or with $10 \mu \mathrm{M} 5$-aza C for the indicated time periods (A, lower image; B, right). MMP-9 activity was determined using gelatin zymography, as described in Materials and methods. (B) Relative MMP-9 activities, quantified densitometrically in ImageJ. The images are representative of three similar experiments (A), or are calculated as means \pm SEM from three independent experiments. ${ }^{*} \mathrm{P}<0.05$ compared with control.
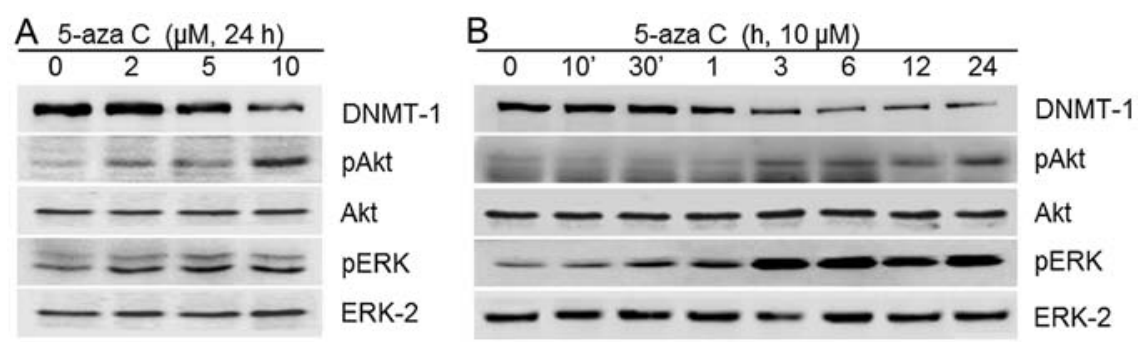

Figure 4. 5-Aza C treatment activates PI3-kinase/Akt and ERK1/2 kinase pathways. HT1080 cells were treated with the indicated 5-aza C concentrations for $24 \mathrm{~h}$ (A) or with $10 \mu \mathrm{M}$ 5-aza C for the indicated time periods (B). DNMT-1, pAkt, Akt, pERK and ERK-2 protein levels were assessed using western blotting with specific antibodies. The images are representative of three independent experiments.

HT1080 cells arrested in the $\mathrm{G}_{2} / \mathrm{M}$ phase increased to 34.8 , 42.9 and $62.8 \%$, respectively (Fig. 1B). These results indicated that 5-aza $\mathrm{C}$ inhibits proliferation in a dose-dependent manner (Fig. 1).

5-Aza C induces migration and invasion of HT1080 cells. Metastatic HT1080 cells possess high migration ability and therefore they are suitable for migration and invasion experiments verifying the effects of 5-aza $\mathrm{C}$ on tumor metastasis. HT1080 24-h exposure to 5-aza C resulted in significant increase in HT1080 cell migration area and induced the spread of HT1080 cells along wound edges, compared with the untreated control cells (Fig. 2A and B). Next, Matrigel invasion assays were performed with 5-aza C-treated HT1080 cells (Fig. 2C). HT1080 cell invasion capacity was significantly induced by 5 -aza $\mathrm{C}$, and the number of invasive cells increased when 5-aza C concentration was increased to $10 \mu \mathrm{M}$ (Fig. 2C). Approximately 29 and 54\% induction in invasion was observed after treatment with 5 and $10 \mu \mathrm{M} 5$-aza C, respectively, compared with the control (Fig. 2C). Both HT1080 migration and invasion were unaffected by $20 \mu \mathrm{M} 5$-aza $\mathrm{C}$ treatment (Fig. 2B and C), most possibly due to a cytotoxic, cell-cycle arresting effect of the compound (Fig. 1B).

5-Aza C induces MMP-9 activity in HT1080 cells. No cytotoxic effect was observed during HT1080 cell treatment with 5-aza C concentrations $<10 \mu \mathrm{M}$ and, therefore, 2-10 $\mu \mathrm{M}$ 5 -aza $\mathrm{C}$ concentrations were used in subsequent experiments. To elucidate the potential mechanisms underlying the metastatic effects of 5-aza C on HT1080 cells, we assessed MMP-9 expression via zymography analysis. As shown in Fig. 3, 5-aza C treatment significantly induced MMP-9 expression in a dose- and time-dependent manner when compared with the control (Fig. 3). These findings suggested that induction of MMP-9 expression might be involved in the increased migration and invasion of HT1080 cells upon 5-aza C treatment.

PI3-kinase/Akt and ERK1/2 MAPK signaling pathways mediate 5-aza C-associated effects in HT1080 cells. To determine whether the MMP-9 activity and metastatic capacities of HT1080 cells induced by 5-aza C were associated with PI3-kinase and mitogen-activated protein kinase (MAPK) signaling pathways, we examined Akt, ERK1/2, p38 kinase and JNK1/2 phosphorylation. As shown in Fig. 4, 5-aza C caused a significant increase in phosphorylated Akt and ERK1/2 levels (Fig. 4). It also activated the p38 and JNK1/2 signaling pathways (data not shown). 5-aza C-induced MMP-9 activity and HT1080 cell metastatic capacities were significantly attenuated after blocking of ERK1/2 and PI3-kinase/Akt with PD and LY inhibitors, respectively (Fig. 5). In contrast, p38 kinase inhibition by SB203580 and JNK1/2 inhibition by SP600125 exerted no apparent effects (data not shown). Collectively, the data indicated that PI3-kinase/Akt and ERK1/2 may be the major pathways mediating 5-aza C-induced MMP-9 activity and metastatic capacities, migration and invasion, of HT1080 cells.

\section{Discussion}

MMPs, a family of zinc-dependent endopeptidases, participate in many physiological and pathological processes (19). Imbalance between MMP inhibition and activation is associ- 
A

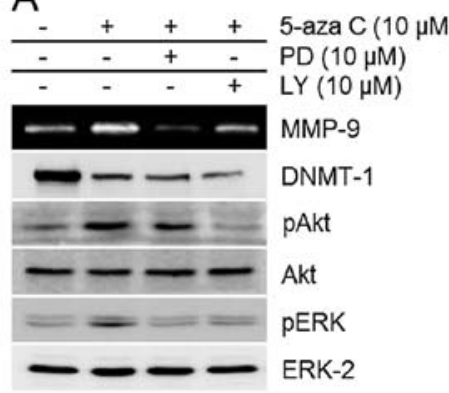

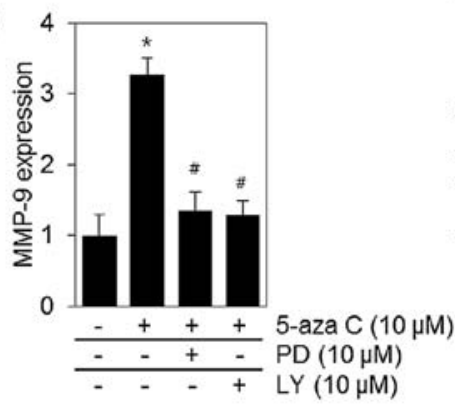

C

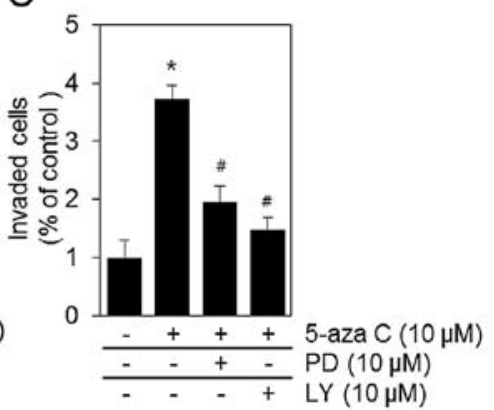

B
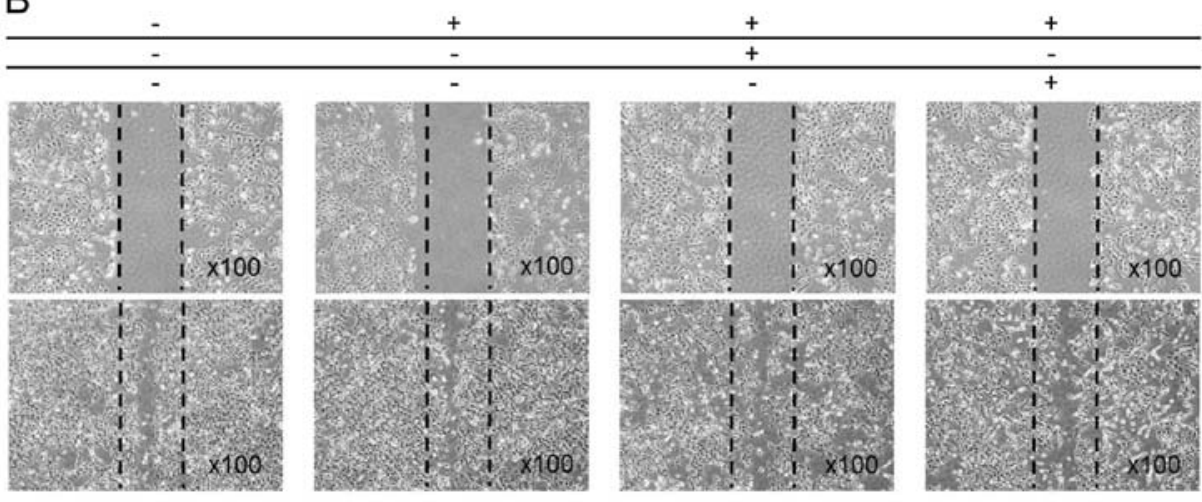

5-aza C $(10 \mu \mathrm{M})$ PD $(10 \mu \mathrm{M})$ LY $(10 \mu \mathrm{M})$

Figure 5. PI3-kinase/Akt and ERK1/2 kinase signaling cascades play crucial roles in 5-aza C-induced metastatic capacities of HT1080 cells. HT1080 cells were treated with $10 \mu \mathrm{M}$ 5-aza C in the absence or presence of ERK1/2 inhibitor PD98059 (PD) and PI3-kinase inhibitor LY294002 (LY). (A) MMP-9 activation, as determined using gelatin zymography (top), and DNMT-1, pAkt, Akt, pERK and ERK-2 levels, as detected by western blotting (bottom). Relative MMP-9 activities were quantified by densitometric measurements with ImageJ (A, right panel). (B) Migratory ability of HT1080 cells, as determined by wound-healing assay. (C) HT1080 invasion ability, as determined by invasion assay. The images are representative of three independent experiments. The data are from three independent experiments and are given as means \pm SEM. ${ }^{*} \mathrm{P}<0.05$ compared with untreated control. ${ }^{~} \mathrm{P}<0.05$ compared with 5 -aza $\mathrm{C}$-treated cells.

ated with various diseases, including osteoarthritis, rheumatoid arthritis, tumor metastasis, and cardiovascular disease (19-21). Secretion of MMPs by structural and inflammatory cells is thought to take part in the processes of cancer metastasis to distant sites $(22,23)$. MMPs are involved in this metastatic progression by initiating turnover of ECM components and modulating cancer cell migration (24). Previous studies have revealed that MMP-9 expression is the strongest in fibrosarcoma cells and has been implicated in tumor invasion and metastasis.

The cancer epigenome is characterized by global alterations in DNA methylation and histone modifications, as well as altered expression profiles of chromatin-modifying enzymes (25). Alteration of global DNA methylation plays a significant role in tumorigenesis and occurs at a variety of genome sequences, including repetitive elements, retrotransposons, CpG-poor promoters, introns and gene deserts (26).

Various epigenetic drugs have been recently identified that can successfully reverse DNA methylation and histone modification abnormalities that occur in cancer (27). DNA methylation inhibitors, such as 5-aza $\mathrm{C}$ and decitabine, promote decrease in DNA methylation, inducing gene expression and differentiation of cultured cells. This facilitates our understanding of the potential use of epigenetic drugs in cancer therapy (28). In addition, DNA methylation inhibitors are in clinical use, as part of anticancer strategy, restoring normal function to abnormally hypermethylated genes (29). In particular, 5-aza $\mathrm{C}$ inhibits tumor cell proliferation by demethylating and reactivating genes silenced by methylation in cervical cell lines CaSki, C-33A, HeLa and SiHa (30). In contrast, 5-aza $\mathrm{C}$ treatment of acute myeloid leukemia might result in enhanced invasiveness of tumor cells via a mechanism involving MMP-9 (31). Previous studies revealed that 5-aza C increased invasiveness of several pancreatic (32) and acute myeloid leukemia cells (31). Similarly, our results indicated that 5-aza C-associated global DNA hypomethylation was accompanied by an increased invasiveness of HT1080 cells.

Considering the above, it is important to understand epigenetic mechanisms used by cells to regulate MMP expression to modulate their invasive properties. In the present study, we focused on the role of DNA methylation alteration in the modulation of MMP-9 activity in human HT1080 fibrosarcoma cells. We demonstrated the biological properties of 5-aza $\mathrm{C}$ by showing that 5-aza $\mathrm{C}$ treatment increased migration and invasion of HT1080 cells and induced MMP-9 activity, possibly via PI3-kinase/Akt and ERK1/2 pathway activation. We observed a significant increase of migration with 5-aza $\mathrm{C}$ concentrations up to $\sim 10 \mu \mathrm{M}$. This effect was abolished in the presence of $20 \mu \mathrm{M} 5$-aza C, probably because of the compound's antiproliferative effect (Fig. 2).

MAPKs regulate cellular responses, including gene expression, cell proliferation, metabolism and migration (33). Various lines of evidence suggest that MMP-9 expression in corneal epithelial cells (34), osteoblast-like MC3T3-E1 cells (35), tracheal smooth muscle cells (36), and breast epithelial cells (37) is increased via MAPKs, ERK1/2, p38 and JNK1/2 activation. The roles of individual MAPKs in MMP expression vary with cell types and stimuli. For example, 
activation of p38 kinase might play a crucial role in transforming growth factor $\beta$-induced corneal epithelial migration in C57BL/6J mice (38), while ERK1/2 and JNK1/2, rather than p38 kinase, have been associated with the regulation of IL-1 $\beta$ induction of MMP expression in corneal fibroblasts (39). PI3-kinase pathway plays a critical role in a variety of cellular processes by phosphorylating its downstream target Akt. These processes include mitogenic signaling, cytoskeletal remodeling, metabolic control and cell survival (40). In the present study, inhibiting PI3-kinase/Akt activity by LY, or ERK1/2 activity by PD, downregulated not only MMP-9 activity but also HT1080 cell migration (Fig. 5).

Collectively, our data suggest that 5 -aza $\mathrm{C}$ may play an important role in tumor invasiveness through MMP-9 modulation. The potential adverse effects of 5-aza $\mathrm{C}$ treatment on tumors need to be evaluated before future clinical applications in therapy of other solid neoplasms.

\section{Acknowledgements}

The present was supported by the National Research Foundation of Korea (NRF) grants funded by the Korea government (MSIP) (nos. 2015R1C1A2A01055015 and 2014R1A1A3049653) and the Korean Health Technology R\&D Project, Ministry of Health \& Welfare, Republic of Korea (A120960-1201-0000300).

\section{References}

1. Avgustinova A and Benitah SA: The epigenetics of tumour initiation: Cancer stem cells and their chromatin. Curr Opin Genet Dev 36: 8-15, 2016.

2. Miremadi A, Oestergaard MZ, Pharoah PD and Caldas C: Cancer genetics of epigenetic genes. Hum Mol Genet 16 (R1): R28-R49, 2007.

3. Bird A: DNA methylation patterns and epigenetic memory. Genes Dev 16: 6-21, 2002.

4. Jovanovic J, Rønneberg JA, Tost J and Kristensen V: The epigenetics of breast cancer. Mol Oncol 4: 242-254, 2010.

5. Jones PA and Baylin SB: The fundamental role of epigenetic events in cancer. Nat Rev Genet 3: 415-428, 2002.

6. Qiu X, Hother C, Ralfkiær UM, Søgaard A, Lu Q, Workman CT, Liang G, Jones PA and Grønbæk K: Equitoxic doses of 5-azacytidine and 5-aza-2'deoxycytidine induce diverse immediate and overlapping heritable changes in the transcriptome. PLoS One 5: e12994, 2010.

7. Snyder RD and Lachmann PJ: Differential effects of 5-azacytidine and 5-azadeoxycytidine on cytotoxicity, DNA-strand breaking and repair of X-ray-induced DNA damage in HeLa cells. Mutat Res 226: 185-190, 1989.

8. Liu Z, Lu H, Liu R, Chen B, Wang S, Ma J and Fu J: The dineolignan from Saururus chinensis, manassantin B, inhibits tumor-induced angiogenesis via downregulation of matrix metalloproteinases 9 in human endothelial cells. Oncol Rep 32: 659-667, 2014

9. Kumta SM, Huang L, Cheng YY, Chow LT, Lee KM and Zheng MH: Expression of VEGF and MMP-9 in giant cell tumor of bone and other osteolytic lesions. Life Sci 73: 1427-1436, 2003.

10. Sato $\mathrm{H}$ and Seiki M: Regulatory mechanism of $92 \mathrm{kDa}$ type IV collagenase gene expression which is associated with invasiveness of tumor cells. Oncogene 8: 395-405, 1993.

11. Iyer V, Pumiglia K and DiPersio CM: Alpha3beta1 integrin regulates MMP-9 mRNA stability in immortalized keratinocytes: A novel mechanism of integrin-mediated MMP gene expression. J Cell Sci 118: 1185-1195, 2005.

12. Ramos-DeSimone N, Hahn-Dantona E, Sipley J, Nagase H, French DL and Quigley JP: Activation of matrix metalloproteinase-9 (MMP-9) via a converging plasmin/stromelysin-1 cascade enhances tumor cell invasion. J Biol Chem 274: 13066-13076, 1999.
13. Watanabe H, Nakanishi I, Yamashita $K$, Hayakawa $T$ and Okada Y: Matrix metalloproteinase-9 (92 kDa gelatinase/type IV collagenase) from U937 monoblastoid cells: Correlation with cellular invasion. J Cell Sci 104: 991-999, 1993.

14. Lyons JG, Birkedal-Hansen B, Pierson MC, Whitelock JM and Birkedal-Hansen H: Interleukin-1 beta and transforming growth factor-alpha/epidermal growth factor induce expression of $\mathrm{M}(\mathrm{r})$ 95,000 type IV collagenase/gelatinase and interstitial fibroblasttype collagenase by rat mucosal keratinocytes. J Biol Chem 268: 19143-19151, 1993.

15. Ito M, Hagiyama M, Mimae T, Inoue T, Kato T, Yoneshige A, Nakanishi J, Kondo T, Okada $\mathrm{M}$ and Ito A: $\alpha$-Parvin, a pseudopodial constituent, promotes cell motility and is associated with lymph node metastasis of lobular breast carcinoma. Breast Cancer Res Treat 144: 59-69, 2014.

16. Wang D, Lu P, Zhang H, Luo M, Zhang X, Wei X, Gao J, Zhao Z and Liu C: Oct-4 and Nanog promote the epithelial-mesenchymal transition of breast cancer stem cells and are associated with poor prognosis in breast cancer patients. Oncotarget 5: 10803-10815, 2014.

17. Yu SM and Kim SJ: Production of reactive oxygen species by withaferin A causes loss of type collagen expression and COX-2 expression through the PI3K/Akt, p38, and JNK pathways in rabbit articular chondrocytes. Exp Cell Res 319: 2822-2834, 2013.

18. Yu SM and Kim SJ: DNA-hypomethylating agent, 5'-azacytidine, induces cyclooxygenase-2 expression via the PI3-kinase/Akt and extracellular signal-regulated kinase-1/2 pathways in human HT1080 fibrosarcoma cells. Int J Oncol 47: 1469-1475, 2015.

19. Yoshihara Y, Nakamura H, Obata K, Yamada H, Hayakawa T, Fujikawa $\mathrm{K}$ and Okada Y: Matrix metalloproteinases and tissue inhibitors of metalloproteinases in synovial fluids from patients with rheumatoid arthritis or osteoarthritis. Ann Rheum Dis 59: 455-461, 2000

20. Spinale FG, Coker ML, Krombach SR, Mukherjee R, Hallak H, Houck WV, Clair MJ, Kribbs SB, Johnson LL, Peterson JT, et al: Matrix metalloproteinase inhibition during the development of congestive heart failure: Effects on left ventricular dimensions and function. Circ Res 85: 364-376, 1999.

21. Stricklin GP and Welgus HG: Human skin fibroblast collagenase inhibitor. Purification and biochemical characterization. J Biol Chem 258: 12252-12258, 1983.

22. Gueders MM, Foidart JM, Noel A and Cataldo DD: Matrix metalloproteinases (MMPs) and tissue inhibitors of MMPs in the respiratory tract: Potential implications in asthma and other lung diseases. Eur J Pharmacol 533: 133-144, 2006.

23. Offersen BV, Pfeiffer P, Andreasen P and Overgaard J: Urokinase plasminogen activator and plasminogen activator inhibitor type-1 in non small-cell lung cancer: Relation to prognosis and angiogenesis. Lung Cancer 56: 43-50, 2007.

24. Kessenbrock K, Plaks V and Werb Z: Matrix metalloproteinases: Regulators of the tumor microenvironment. Cell 141: 52-67, 2010.

25. Zhang Z and Zhang R: Epigenetics in autoimmune diseases: Pathogenesis and prospects for therapy. Autoimmun Rev 14: 854-863, 2015.

26. Rodriguez J, Frigola J, Vendrell E, Risques RA, Fraga MF, Morales C, Moreno V, Esteller M, Capellà G, Ribas M, et al: Chromosomal instability correlates with genome-wide DNA demethylation in human primary colorectal cancers. Cancer Res 66: 8462-9468, 2006.

27. Yoo CB and Jones PA: Epigenetic therapy of cancer: Past, present and future. Nat Rev Drug Discov 5: 37-50, 2006.

28. Constantinides PG, Jones PA and Gevers W: Functional striated muscle cells from non-myoblast precursors following 5-azacytidine treatment. Nature 267: 364-366, 1977.

29. Alexander VM, Roy M, Steffens KA, Kunnimalaiyaan M and Chen H: Azacytidine induces cell cycle arrest and suppression of neuroendocrine markers in carcinoids. Int J Clin Exp Med 3: 95-102, 2010.

30. Wu Y, Meng L, Wang H, Xu Q, Wang S, Wu S, Xi L, Zhao Y, Zhou J, Xu G, et al: Regulation of DNA methylation on the expression of the FHIT gene contributes to cervical carcinoma cell tumorigenesis. Oncol Rep 16: 625-629, 2006.

31. Bernal T, Moncada-Pazos A, Soria-Valles C and GutiérrezFernández A: Effects of azacitidine on matrix metalloproteinase-9 in acute myeloid leukemia and myelodysplasia. Exp Hematol 41: 172-179, 2013. 
32. Sato N, Maehara N, Su GH and Goggins M: Effects of 5-aza2'-deoxycytidine on matrix metalloproteinase expression and pancreatic cancer cell invasiveness. J Natl Cancer Inst 95: 327-330, 2003.

33. Johnson GL and Lapadat R: Mitogen-activated protein kinase pathways mediated by ERK, JNK, and p38 protein kinases. Science 298: 1911-1912, 2002.

34. Kim HS, Luo L, Pflugfelder SC and Li DQ: Doxycycline inhibits TGF-beta1-induced MMP-9 via Smad and MAPK pathways in human corneal epithelial cells. Invest Ophthalmol Vis Sci 46: 840-848, 2005

35. Chia-Lan T, Chen WC, Hsieh HL, Chi PL, Hsiao LD and Yang CM: Erratum to: TNF-alpha induces MMP-9 expression and soluble ICAM-1 release via TRAF2, c-src, MAPKs and NF-kappaB in osteoblast-like MC3T3-E1 cells. J Biomed Sci 22: 20, 2015. doi: 10.1186/s12929-015-0119-1.

36. Liang KC, Lee CW, Lin WN, Lin CC, Wu CB, Luo SF and Yang CM: Interleukin-1beta induces MMP-9 expression via p42/p44 MAPK, p38 MAPK, JNK, and nuclear factor-kappaB signaling pathways in human tracheal smooth muscle cells. J Cell Physiol 211: 759-770, 2007.
37. Reddy KB, Krueger JS, Kondapaka SB and Diglio CA: Mitogenactivated protein kinase (MAPK) regulates the expression of progelatinase B (MMP-9) in breast epithelial cells. Int J Cancer 82: 268-273, 1999.

38. Saika S, Okada Y, Miyamoto T, Yamanaka O, Ohnishi Y, Ooshima A, Liu CY, Weng D and Kao WW: Role of p38 MAP kinase in regulation of cell migration and proliferation in healing corneal epithelium. Invest Ophthalmol Vis Sci 45: 100-109, 2004.

39. Lu Y,Fukuda K, Liu Y,Kumagai N and Nishida T: Dexamethasone inhibition of IL-1-induced collagen degradation by corneal fibroblasts in three-dimensional culture. Invest Ophthalmol Vis Sci 45: 2998-3004, 2004.

40. Wymann MP and Pirola L: Structure and function of phosphoinositide 3-kinases. Biochim Biophys Acta 1436: 127-150, 1998. 